Kujansuu, P., Lehtovaara, J., Grönvall, M., Seppänen, O., and Peltokorpi, A. (2019). "Comparison of Collaboration and Trade Partner Commitment in Takt Implementation Cases." In: Proc. 27th Annual Conference of the International. Group for Lean Construction (IGLC), Pasquire C. and Hamzeh F.R. (ed.), Dublin, Ireland, pp. 1219-1228. DOI: https://doi.org/10.24928/2019/166. Available at: <www.iglc.net>.

\title{
COMPARISON OF COLLABORATION AND TRADE PARTNER COMMITMENT IN TAKT IMPLEMENTATION CASES
}

\author{
Pekka Kujansuu', Joonas Lehtovaara², Max Grönvall ${ }^{3}$, Olli Seppänen ${ }^{4}$, and Antti \\ Peltokorpi ${ }^{5}$
}

\begin{abstract}
This study addresses the possible ways to improve takt implementation in projects. The purpose of this study is to gain knowledge of the stakeholder commitment and collaboration in takt projects where takt production is implemented. The study aims to explore which enablers and barriers affect collaboration in takt implementation projects, and how they differ between cases in Finland and California.

The study was conducted as a qualitative multiple case study. The case projects were purposefully chosen for this study. The data collection was conducted as a triangulation of interview, observation and documentation observation. The enablers and barriers from different cases were clustered into plusses, deltas, and drivers between Finnish and Californian cases as well as jointly. The results were then analysed in a workshop and recommendations for further takt implementations as well as further research were made.

Recommended actions for further takt implementation cases of more complete Lean understanding, and more transparent partnership between trade partners. However, the results and recommendations are based on a single study with a limited amount of cases, and therefore further research inside the topic is needed.
\end{abstract}

\section{KEYWORDS}

takt production; collaboration; stakeholders; implementation

\section{INTRODUCTION}

Tools for production planning in construction have developed significantly during the past two decades. The possibility of turning the construction from resource to flow-efficient production has been demonstrated with tools such as Last Planner System (LPS) (Ballard 2000) and takt production methods such as Takt Time Planning (Frandson et al. 2013) and

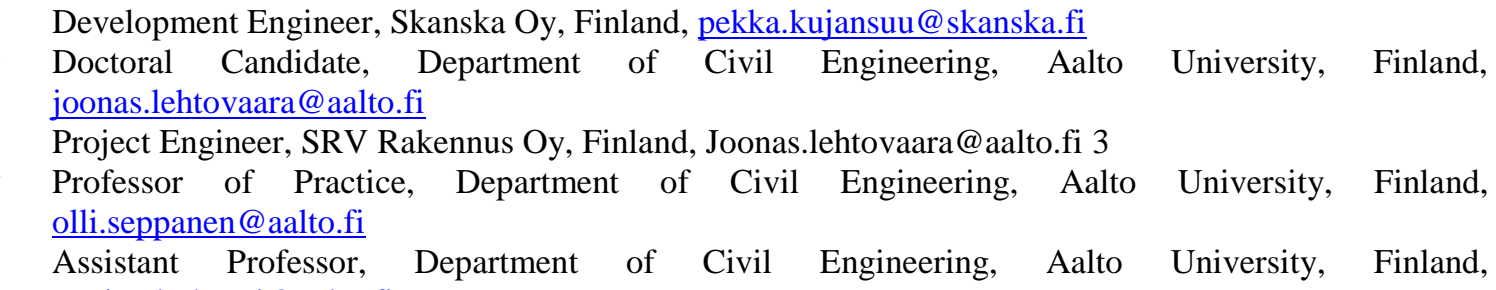
antti.peltokorpi@aalto.fi 
Takt Planning and Takt Control (Dlouhy \& Binninger 2016). Takt, a concept originated from lean manufacturing, represents a "beat" of the production and refers to a predefined interval of time where one set of work is done (Hagsheno et al. 2016). Takt production has lately received significant attention inside the lean construction community. The improvement of flow efficiency inside the production has been documented in several occasions, for example, Frandson et al. (2013;2014), Vatne \& Drevland (2016) and Binninger et al. (2018). In addition to the existing literature, takt implementation in the construction industry is going forward in several ongoing implementation cases.

Previous results indicate that understanding social aspects better in takt production could lead to remarkable benefits (Tommelein 2017). Frandson et al. (2013) stated that "in order to improve production slightly, crews just have to work a little bit harder; however, to improve production dramatically, the entire team must work together and really think about every task." Frandson \& Tommelein (2016) mentioned how the general contractor and the trade partners evolved to become a production team, which was able to plan the production more collaboratively. However, little research yet exists on the broader collaboration aspect of takt production, and the research has been mostly focusing on developing technical methods in use. The comparison of the collaboration of different stakeholders between different takt implementation cases has also been limited.

More research is needed on how the collaboration is utilized in takt cases, and how different social barriers and enablers affect on implementation of takt methods. Lately, several takt production pilots have been performed in Finland, which have partially utilized the methods described by Frandson et al. (2013). However, the working culture in takt production and collaboration between different stakeholders in Finnish takt cases has not been studied yet. It would be beneficial to understand how the barriers and enablers vary between different implementation cases, and how the collaboration aspect is managed in California and what kind of improvements could be brought to different entities, such as Finland.

The scope of this study is to find possible similarities and ways to improve the collaboration between different stakeholders in takt cases, by comparing the social barriers and enablers from different case projects. The study aims to answer the following questions: 1) What kind of social barriers, enablers, and drivers effect collaboration in takt projects between different cases? 2) How the working culture in takt projects in Finland could be improved by implementing Californian takt practices?

\section{RESEARCH METHOD}

\section{Case STUdY}

The study was conducted as a multiple case study with purposeful sampling. Purposeful sampling is commonly used in qualitative research when resources are limited in information-rich cases (Patton 2002). The case projects were chosen to represent two different working cultures and different views as well as different maturity level in takt related construction projects. The study contains two cases for each of the two views for validity purposes. 
The more matured way, which is referred in this study as the Californian way, has been used and documented on multiple occasions by Frandson \& Tommelein (e.g., 2013, 2015, 2017). The Californian way can be seen as a six-step method presented by Frandson et al. (2013), 1) Gather information, 2) Define zones, 3) Understand the Trade sequence, 4) Balance the workflow, 5) Understand the Individual Trade Duration, 6) Production planning.

The Finnish way of implementing takt has not been yet documented in the literature. However, the process of the Finnish way used in the Finnish cases echoes partially from the Location-Based Management System (LBMS, Seppänen \& Kenley 2010). LBMS is a method of construction planning and production control based on the movement of resources through the construction site, aiming to maximize continuous use of labor and productivity, reduce waste and risk, increase transparency and improve predictability and flow (Kenley and Seppänen 2010). Frandson et al. (2015) compared the similarities and differences between LBMS and takt time planning which showed a lot of similarities and few differences. Both methods aim for continuous flow of work through production areas at a set beat for each phase of work. (Frandson et al. 2015) Even though the case projects from different regions varied from their grounding of implementing takt production, they were seen as an adequate match concerning the subject under study.

\section{METHODS OF DATA COLLECTION AND ANALYSIS}

The data was collected as a triangulation of interview, observation and document familiarization in all of the four cases. The interviews focused on production planning and control as well as social and technical sides of those aspects. The interviews also included in-depth 5-why analysis concerning social enablers and barriers of production planning and control. Observations were carried out as site visits along with participation on multiple trade partner meetings. The focus during the observations were pointed on production and especially on the interaction between different trade partners. The documents which were familiarized were production plans, blueprints, and other production related documents. A cross-analysis from the collected data were carried out by the authors where the founded social aspects were divided into three different clusters as plusses, deltas and to drivers influencing these effects.

\section{CASE DESCRIPTIONS}

The study compares four cases, (Table 1.), which are from Finland and California. Two of the studied cases were residential construction projects located in Finland. Two other cases were located in California and were multi-storey medical and research facilities.

The cases from Finland were a seven-storey residential building and a six storey residential building for students located in Helsinki area. Both cases used an intensive 1day takt. Takt production plan was used in the interior and finishing phases of the project. Both of the cases used takt planning methods to radically decrease the durations of the interior phases.

The case projects from California were both multi-storey medical and research facilities located in Northern California. The production plan in both of the cases based on the six- 
step method by Frandson et al. (2013). During the study, the first case was in its interior and finishing phase and used a 5-day takt. The second case was in its core phase and used a 5 and 4-day takt. During this study, the interior phase was still under planning. Both cases used takt planning as a method to gain savings in the total duration and to make the production more stable.

Table 1: Case project basic information

\begin{tabular}{ccccc}
\hline Information & $\begin{array}{c}\text { Finland } \\
\text { case 1 }\end{array}$ & $\begin{array}{c}\text { Finland } \\
\text { case 2 }\end{array}$ & $\begin{array}{c}\text { California } \\
\text { case 1 }\end{array}$ & $\begin{array}{c}\text { California } \\
\text { case 2 }\end{array}$ \\
\hline Type of project & $\begin{array}{c}\text { Residential } \\
\text { building }\end{array}$ & $\begin{array}{c}\text { Residential } \\
\text { building }\end{array}$ & $\begin{array}{c}\text { Multi-storey } \\
\text { medical \& } \\
\text { research facility }\end{array}$ & $\begin{array}{c}\text { Multi-storey } \\
\text { medical \& } \\
\text { research facility }\end{array}$ \\
Takt time & 1 day & 1 day & 5 days & 4 \& 5 days \\
Takt & $\begin{array}{c}\text { Interior and } \\
\text { finishes }\end{array}$ & $\begin{array}{c}\text { Interior and } \\
\text { finishes }\end{array}$ & $\begin{array}{c}\text { Core, interior, } \\
\text { and finishes }\end{array}$ & Core \\
$\begin{array}{c}\text { Objective of } \\
\text { takt }\end{array}$ & $\begin{array}{c}\text { Shorter duration } \\
\text { compared to } \\
\text { projects } \\
\text { executed without } \\
\text { takt }\end{array}$ & $\begin{array}{c}\text { Shorter duration } \\
\text { compared to } \\
\text { projects } \\
\text { executed without } \\
\text { takt }\end{array}$ & $\begin{array}{c}\text { Shorter duration } \\
\text { compared to } \\
\text { projects } \\
\text { executed without } \\
\text { takt and better } \\
\text { stability }\end{array}$ & $\begin{array}{c}\text { Shorter duration } \\
\text { compared to } \\
\text { projects }\end{array}$ \\
$\begin{array}{c}\text { executed without } \\
\text { takt and better } \\
\text { stability }\end{array}$ \\
\hline
\end{tabular}

\section{RESULTS AND ANALYSIS}

The data collected from the different cases were evaluated and analysed by the authors, and the social aspects were divided into three different clusters as plusses, deltas and to drivers influencing these effects (Table 2). Plusses represent objects that succeeded, deltas represent the objects that need to be improved and drivers represent objects and entities that especially helped the project to succeed. 


\section{Plusses, Deltas, AND DRIVERS}

Table 2: Unique and common plusses, deltas, and drivers

\begin{tabular}{|c|c|c|}
\hline Finland & California & Both \\
\hline Plusses: & Plusses: & Plusses: \\
\hline $\begin{array}{c}\text { Technical capability in } \\
\text { production planning } \\
\text { Potential of technological } \\
\text { development }\end{array}$ & $\begin{array}{l}\text { Trust between GC, trade } \\
\text { partners, and client } \\
\text { Lean leadership }\end{array}$ & $\begin{array}{c}\text { Quick results } \\
\text { Increased stability }\end{array}$ \\
\hline Deltas: & Deltas: & Deltas: \\
\hline $\begin{array}{l}\text { Ineffective contract models } \\
\text { Lack of leadership and } \\
\text { knowledge in lean principles }\end{array}$ & $\begin{array}{c}\text { Trade partner resourcing } \\
\text { Trade partner commitment at } \\
\text { the beginning }\end{array}$ & $\begin{array}{l}\text { Understanding of resource vs } \\
\text { flow efficiency } \\
\text { Resistance towards new } \\
\text { methods }\end{array}$ \\
\hline $\begin{array}{l}\text { Drivers: } \\
\text { Proactivity and commitment of } \\
\text { project crew and key subs }\end{array}$ & $\begin{array}{c}\text { Drivers: } \\
\text { Knowledge in takt production } \\
\text { Lean culture }\end{array}$ & $\begin{array}{c}\text { Drivers: } \\
\text { Takt experts } \\
\text { Project crew } \\
\text { Daily huddles } \\
\text { Visualization of plans }\end{array}$ \\
\hline
\end{tabular}

\section{Observations that were unique for the Finnish cases}

In both Finnish implementation cases, strong knowledge in production planning and continuous support from office to the site was recognized as efficient enablers for successful implementation of takt production. Especially the main contractor's firm understanding of location-based planning provided a solid ground for piloting intensive 1day takt. As the supporting operations continuously helped in the planning phase, the starting point for technically effective takt was developed. Also, in case 1 the implementation of new digital production planning tools were recognized as a potential enabler for continuous learning in the long term.

Conflicting contract models with lack of lean leadership and trust between parties were the most visible deltas. It was quickly recognized that the old contract models did not support flow-efficiency and intensive requirements of short takt, while the subcontractors were not aware of the requirements or benefits of the new method of working. The lack of disciplined lean leadership and thorough understanding of lean principles from the general contractor was seen as a delta towards collaboration, which also affected negatively towards the trust between the general contractor and the subcontractors. Even though the leadership would have been adequate for "traditional" project management, it did not meet the requirements for a situation where intensive change management was needed. Problems were also partly caused by the nature of the pilot projects, where the persons in charge were not yet aware of the tight requirements for the lean leadership from the beginning.

However, the proactivity, commitment, and positive attitude towards learning by the site managers and the key subcontractors (for example, HVAC in Finland case 1) were 
seen as drivers for success. Their ability to adapt and contribution to innovating solutions together during the production was seen as a clear enabler, which developed the process from the starting point. A collaborative planning session between the GC and subcontractors is illustrated in Figure 1.

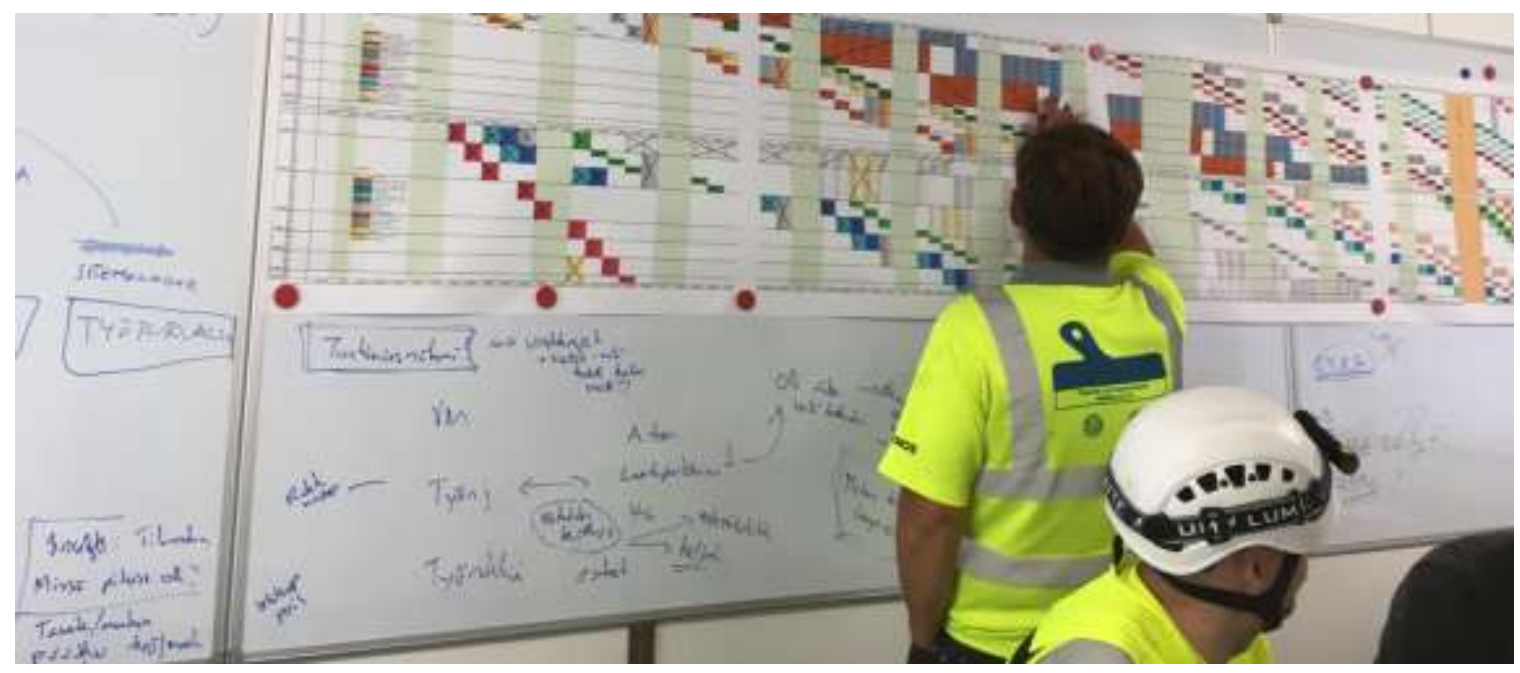

Figure 1: A planning session in Finland case 1

\section{Observations that were unique for the California cases}

In the California cases, (Figure 2), mutual trust between the general contractor and subcontractors was found to be a plus, regarding the collaboration between different stakeholders. The first indication of that was the fact that the subcontractors were defined and treated as trade partners, which refers to equal partnership instead of a hierarchic allocation. The atmosphere inside trade partner meetings indicated that a mutual trust and team spirit between general contractor and trade partners was on high level. For example, the General Superintendent treated everyone participating in the trade partner meeting as an equal and made everyone feel that they were part of a team. Drivers affecting the mutual trust was found in the general contractor's level of knowledge in takt time planning as well as in their strong culture in lean construction and lean leadership.

The strong lean culture and leadership appeared in the Big Room usage as well as in the lean spirit inside site offices. For example, inside the site offices, there were posters with lean statements, such as the eight deadly wastes, plusses/deltas charts, and vision and values regarding the current project. The usage of the Big Room facility was seen helpful in building collaboration as well as sharing information with project stakeholders. Disciplined but soft leadership skills seemed to create trust between the stakeholders. The trust between the general contractor and the client was also seen as a driver towards stronger collaboration.

Deltas were found in the trade partners resourcing with the takt production. The resource changes within different takt areas created difficulties for some of the key trade partners. Another delta was found in the trade partner commitment to takt production. There had been a situation where a certain trade partner had to be changed do to disagreements in the view of production planning. 


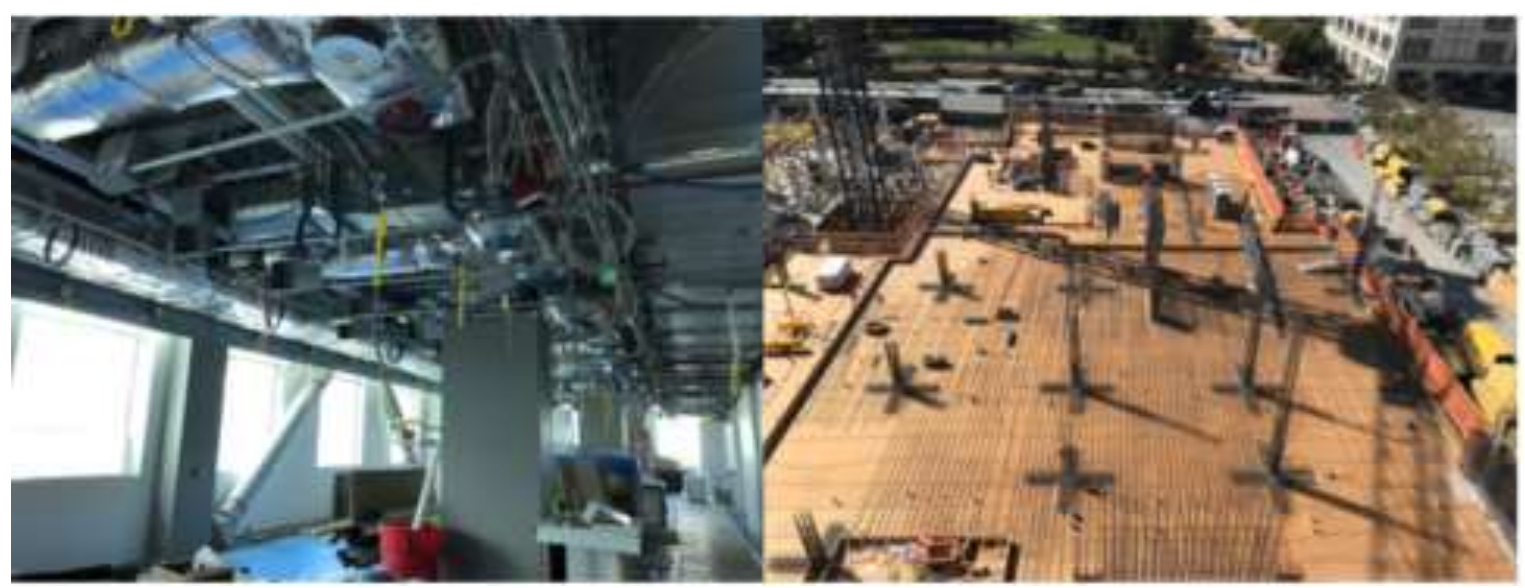

Figure 2: California case site views

\section{Similarities between cases}

Several similarities were found between the cases. The quick visible results in production and the more reliable production plan was found as a common plus in all of the cases. The highly visual and logical production plan affected positively on developing trust between stakeholders as well as helped them to gain mutual understanding during the projects. The common view of production plan created stability throughout the projects.

The positive feeling evolving from successful takt cases was found as a driver towards better collaboration within stakeholders. The help and commitment of takt experts, such as researchers, was found as a key driver in the creation of a common path for collaboration. The output from the open-minded project crews was equally important, as they were the ones who made the collaboration between stakeholders possible. Daily huddles were seen as a potential way to start a working day with the sharing of information and reviewing the progress of the previous day.

Common deltas between the cases were found in the mindset of certain stakeholders. Trade partners had problems in the ability to see the difference between resource efficiency and flow efficiency. This was seen as a common barrier in all of the cases and it complicated the production planning and control. Other common deltas were the lack of understanding takt as a method and the fear of new ways of working, which were seen as a common barrier for effective implementation.

\section{DISCUSSION AND RECOMMENDATIONS}

The Californian cases focused and relied more on the social aspects and trust between stakeholders, while the Finnish cases focused on the technical side of production planning by the general contractor. The strong lean culture imposed by the general contractor from the California cases were a big factor in the building of collaboration between stakeholders, and the proving ground for the creation of transparent processes.

The strong knowledge in the technical side of production planning can be seen as a good base for takt production development in Finland. In contrast, the biggest development areas seem to be on the social side and in the collaboration between trade partners and 
especially between subcontractors. The trust between stakeholders can make a great impact on production planning when transparency and teamwork between different sides is mutual.

The problem with takt production and the contract models in the Finnish cases brings up the question: Should the contracts between the general contractors and subcontractors be strict and well takted, or could the right way be more dependent on trust and openness between the parties?

The model of Social Subcontract presented by Priven \& Sacks (2016) with LPS improved the coordination of the projects compared to projects that used LPS alone. Priven $\&$ Sacks (2016) describe that the Social Subcontract aims to strengthen the collaboration between the general contractor and the subcontractors as well as to guide them towards the common goal. Social Subcontract process consists of multiple meetings with the GC and all of the subcontractors involved in the project. Within these meetings, all the subcontractors are given an opportunity to express their needs and specific steps for productive work and to discuss about them with each other to gain a more complete overview of the production of the project. Within these meetings, a more collaborative relationship is formalized between the subcontractors and the GC and the common goal is expressed as a written agreement signed by all the participants. The agreement is then monitored in beforehand agreed meetings. These meetings include a peer-evaluation between the GC and all of the subcontractors where everyone has to evaluate each other. The sanction of social shaming was seen as the matter that maintains a commitment to the agreement (Priven \& Sacks 2016.) There was also a strong positive effect on the general contractor's motivation to improve the make-ready process for the overall flow of the project when the subcontractors were better included in the production planning phase (Priven \& Sacks 2016). There seems to be a pattern in reliability and trust between stakeholders with the efficiency of production. Therefore, it could be assumed that takt production could benefit from SSub, too.

Finnish cases provided excellent results for pilots by radically reducing the duration while the quality and costs remained the same. However, it is clear that in order to develop the process further a better collaboration between the stakeholders is vital. Aspects that should be taken in consideration in the future development are deeper and more specific collaboration in the production planning with the subcontractors, consideration of SSub model with known partners and the augmentation of lean as a way of working.

The limitations of this study include the limited amount of inspected projects, the limited amount of time observed in the California cases, and that the observation was done between residential and medical facility cases. Taking these limitations into consideration the findings are still noteworthy.

\section{CONCLUSIONS}

The object of this study was to address and compare possible similarities in collaboration between different stakeholders in takt implementation cases. There was also a goal to find possible ways to improve collaboration in future takt implementation cases in Finland. 
The study addressed multiple enablers, barriers, and drivers, which were seen influencing the collaboration between stakeholders in takt implementation cases. Even though the maturity level in takt production between Finnish and Californian cases varied, a common view regarding the importance of stakeholder collaboration was seen.

The study also aroused similarities between cases from Finland and California as well as possible ways for improvement in the collaboration between different stakeholders in future takt implementation cases in Finland. The maturity level of takt production in the construction industry in Finland is currently low and the use of old fashioned and strict contract models were seen as a problem. An opportunity for better trade partner commitment in near future takt implementation cases was seen possible with more open contract models.

\section{ACKNOWLEDGMENTS}

We would like to thank Adam Frandson and Cory Hackler for the support in data gathering. The research was supported by the Building 2030 consortium of Aalto University and 17 companies. www.building2030.com

\section{REFERENCES}

Ballard, H. (2000). The last planner system of production control.

Binninger, M., Dlouhy, J., Müller, M., Schattmann, M., \& Haghsheno, S. (2018). Short Takt Time in Construction - a Practical Study. Proceedings (IGLC 26). Chennai, India.

Dlouhy, J., Binninger, M., Oprach, S., \& Haghsheno, S. (2016). Three-level method of Takt planning and Takt control-A new approach for designing production systems in construction. Proceedings (IGLC 24). Boston, USA.

Frandson, A., Berghede, K., \& Tommelein, I. D. (2013). Takt time planning for construction of exterior cladding. Proceedings (IGLC 21). Fortaleza, Brazil.

Frandson, A.G, Berghede, K., \& Tommelein, I.D (2014). Takt-Time Planning and the Last Planner. Proceedings (IGLC 21). Oslo, Norway.

Frandson, A.G., Seppänen, O., \& Tommelein, I.D. (2015). Comparison Between Location Based Management and Takt Time Planning. Proceedings (IGLC 23). Perth, Australia, pp. 3-12

Frandson, A. G., \& Tommelein, I. D. (2016). Takt time planning of interiors on a Pre-Cast hospital project. Proceedings (IGLC 24). Boston, USA.

Hasgsheno, S. Binninger, M. Dlouhy, J. \& Sterlike, S. (2016). History and Theoretical Foundations of Takt Planning and Takt Control. (IGLC 24) Proceedings. Boston, MA,USA, sect.1 pp. 53-62

Kenley, R. \& Seppänen, O. (2010). Location-based Management System for

Construction: Planning, Scheduling and Control. London and New York: Spon Press.

Tommelein, I. D. (2017). Collaborative Takt Time Planning of Non-Repetitive Work. Proceedings (IGLC 25). Heraklion, Greece.

Patton, M. Q. (2002). Qualitative research and evaluation methods (3rd ed.). Thousand Oaks, CA: Sage. 
Kujansuu, P., Lehtovaara, J., Grönvall, M., Seppänen, O., and Peltokorpi, A.

Priven, Vitaliy \& Sacks, Rafael. (2016). Impacts of the Social Subcontract and Last Planner System Interventions on the Trade-Crew Workflows of Multistory Residential Construction Projects. Journal of Construction Engineering and Management.

Vatne, M. E., \& Drevland, F. (2016). Practical Benefits of Using Takt Time Planning: A Case Study. Proceedings (IGLC 24). Boston, USA. 